\title{
A New Approach to the Evolution of Collaboration Platforms: The Case of South Korea's Convergence Alliances
}

\author{
Heeyoung Jang \\ Korea Institute of Industrial Technology \\ hjang@kitech.re.kr \\ Jongho Lee \\ Korea Institute of Industrial Technology \\ Jongho88@kitech.re.kr \\ Minsun Kim \\ Korea Institute of Industrial Technology \\ kimms62@kitech.re.kr
}

\author{
Sungmin Cho \\ Korea Institute of Industrial Technology \\ chosm@kitech.re.kr
}

\author{
Hongbum Kim* \\ Korea Institute of Industrial Technology \\ hkim74@kitech.re.kr \\ * Corresponding author
}

\begin{abstract}
While organizations and alliances for collaboration have been promoted by governments for many years, their performance has not been very meaningful in terms of activation or outcome, particularly in South Korea. Thus, as a tool for creating new industries and growth engines, a new form of collaboration platform-convergence alliances-is being promoted in South Korea. In order to explore the distinct characteristics and advantages of convergence alliances, this research compares this new type of platform with existing collaboration platforms. By using a case analysis framework with in-depth interviews, this research suggests several implications for promoting convergence alliances, including the combination of manufacturing and service industries, more opportunities for small- and medium-sized enterprises, the avoidance of opportunistic behaviors, the development of new types of objectives, and the introduction of relevant policy actions and government support.
\end{abstract}

\section{Introduction}

Recently, South Korea (hereafter, Korea) has been facing difficulties in achieving new industrial growth. While Korea has demonstrated remarkable levels of economic growth not seen in any other country in the twentieth century, the speed of economic growth has been relatively stagnant in the twenty-first century. The successful transition from light industry to heavy industry and information and communication technology led Korea to become one of the fastest growing economies in the twentieth century. However, since 2000, there have been no new industries that can generate economy leverage in Korea.

Many studies have demonstrated that among the various factors affecting Korea's rapid economic growth in the twentieth century, government-led industrial policies were the main cause of the economic development (e.g., [1]). However, in the current complex economic environment, arguments for maintaining government-led industrial policies are now not appropriate and this is why a new type of economic growth paradigm is necessary.

The government, media, scholars, and practitioners now emphasize that new strategies for economic growth must be developed that will help Korea adapt to the era of the Fourth Industrial Revolution. Since being included as the main agenda at the 2016 World Economic Forum [2], the Fourth Industrial Revolution has become a very important and frequently used key phrase in politics, economics, and society in Korea. Firms are attempting to improve their core competencies in order to survive the endless competition of the Fourth Industrial Revolution era. For activating private sector-driven growth, Korea's government has also suggested several policy actions for creating new industries (e.g., [3]). Specifically, these policy actions focus on establishing supportive institutions and providing direct support to small and medium-sized enterprises (SMEs). For example, the government is conducting active deregulation in order for new business models to be easily marketed and is switching its system from uniform and balanced support to open, innovative, and challengeable support.

One remarkable policy action is the support of collaboration platforms. Many collaboration platforms comprising industry, academia, research institutes, and other innovation actors have been established for achieving common objectives. However, the collaboration platform pursued by recent policy action, 
the 'convergence alliance,' has expanded both vertically and horizontally. In addition to the traditional concept of strategic or R\&D alliances [4] [5] [6], the convergence alliances in this study include convergence characteristics, namely, actors and technologies from heterogeneous knowledge areas converging for innovation activities. Furthermore, in order to create more varied and practical outcomes, convergence alliances are implemented differently compared to publicly led collaboration platforms. While government and public research institutes are also included in convergence alliances, their participation is only permitted based on the needs of the incumbents.

Although various organizations or alliances for collaboration have been promoted by the government for many years, their contribution to the economy was not so meaningful in terms of activation or outcome. Despite this, the importance of cross-organizational relationships was still emphasized [7], and the government recognized the need for consistent support, resulting in appropriate policy actions. In other words, it is necessary to compare traditional collaboration platforms and the newly emerging platform, the convergence alliance, and analyze their structure, organization, and the way they operate in order to understand the evolution of the new direction of collaboration platforms.

The purpose of this research is to explore the convergence alliance as a collaboration platform and to compare it with different collaboration platforms. In order to analyze its advantages, we reviewed several materials including newspapers, government publications, industrial reports, and research papers, and conducted in-depth interviews to collect supplementary information. As a theoretical lens, studies in technology innovation and management were reviewed and discussed, and several implications were elicited for the further evolution of collaboration platforms.

The remainder of this paper is set out as follows. First, the research methodology is provided in Section 2. The background, needs, and status of convergence alliances are reviewed in Section 3. Next, the current popular collaboration platforms worldwide are explored in Section 4 and compared to convergence alliances for case analysis in Section 5. Discussion is made and several implications are suggested in Section 6 , and finally the conclusion and limitations are presented in Section 7.

\section{Research methodology}

For the comparison between collaboration platforms, this research uses a case analysis framework.
The case study has been widely used in similar research because it is appropriate for comparing complex organizational structures. Specifically, as the primary concerns of the study, collaboration platforms are procedurally contrasting organizations [8]. Therefore, it is useful to adopt the case study framework.

As a theoretical lens, this study uses technology innovation and management literature. Analogous to the knowledge ecology, the field of innovation management primarily covers networks, collaboration, and alliances for the innovative activities of organizations [9].

We gathered data from various sources. First, we reviewed policy and research papers and media articles published by governments, organizations, and associated institutes. We also reviewed annual reports that each convergence alliance published at the end of the year 2017. In addition, for an objective perspective, we explored media articles and industry reports. Finally, we conducted in-depth interviews with the administrative organization of each convergence alliance to gather supplementary data on their backgrounds, processes, discourses, and other evidence that could not be found elsewhere. Specifically, the main content of the in-depth interviews were current collaborations with other organizations, new collaboration plans with different convergence alliances, expected R\&D projects and business models, the need for government support, and difficulties in operating convergence alliances. The interviews were conducted face-to-face in several different meetings for three weeks from June to July 2017.

Additionally, for the validation of collected data, we conducted validity procedures [10] including peer reviews by independent researchers in academia, government, and research institutes. While they were external to this study, they are familiar with the history and structure of convergence alliances. The collected data were thoroughly audited, reviewed, and confirmed by the researchers and thus the credibility of the qualitative data was established. Table 1 summarizes the in-depth interviews and the validation procedures.

\section{Convergence alliance: Its meaning and status}

For the development of new industries, the convergence between technologies and sectors is important. For example, an automobile produced today can be considered as a convergence product with connectivity technology that enables two-way communication. Moreover, it is evolving into a smart car that comprehensively considers different 
Table 1. Summary of data collection

In-depth interview

\begin{tabular}{c|c}
\hline Sector & \# of Interviewees \\
\hline Industry & 7 \\
\hline Government & 1 \\
\hline Research institute & 1 \\
\hline Public organization & 6 \\
\hline Total & 15 \\
\hline
\end{tabular}

environments such as pedestrians, traffic, and other vehicles.

Considering this background, this study defines convergence alliances as collaboration platforms among homogeneous and heterogeneous firms and other related organizations pursuing common objectives such as new business model creation, research and development (R\&D) investment, and overseas market projects. While the primary objectives are different in terms of each convergence alliance, this type of collaboration platform attempts to create new growth by increasing the possibility of success and decreasing uncertainty and risk.

As a representative example, the automobile convergence alliance founded in December 2015 demonstrates several characteristics of a convergence alliance. As automobiles are evolving into smart cars, six firms established a convergence alliance in order to collaborate with each other and create new business models. Initially, only one firm from each sector including the automobile, electronics, Internet, material, telecommunication, and software sector joined and launched the convergence alliance. Soon after, many other firms wanted to participate in the convergence alliance for the establishment of an automobile convergence ecosystem. Three months later, fifty firms were divided into four different branches that each had their own objective. As of June 2018, more than 130 organizations including research institutes and associations were collaborating as various working groups.

Currently, seventeen convergence alliances are being operated. Supported by the Ministry of Trade, Industry and Energy, and pursuing their unique objectives, there have been four main outcomes from these convergence alliances. First, new business models and opportunities have emerged in the new industry. SMEs struggle with commercialization and such convergence alliances assist SMEs in finding new
Validation procedure

\begin{tabular}{c|c}
\hline Sector & \# of validations \\
\hline Academia & 1 \\
\hline Government & 2 \\
\hline Research institute & 3 \\
\hline Total & 6 \\
\hline
\end{tabular}

markets. In particular, large companies in convergence alliances can become a direct customer of SMEs. For the growth of related applications, several business models were created as a platform-based service, such as content production platforms and healthcare data analysis platforms. Figure 1 illustrates examples of these business models.

Second, in order to remove the entry barriers for new industries, the convergence alliances attempted to amend the regulatory frameworks. For example, new discount systems for the diffusion and extension of discounted price offers were provided by amending existing laws and mandatory rules in order to promote commercialization of new technology and product. Establishing new guidelines, amending industrial classification for new industries, and the development of new certification systems were also promoted.

Third, convergence technology R\&D was developed in cooperation with the convergence alliances. While this is similar to other collaboration platforms pursuing R\&D collaboration, this type of technology $R \& D$ focuses on the collaboration of multiple industries. Particularly, R\&D Program Directors who oversee national R\&D plans, join the convergence alliance activities to link several national R\&D projects directly.

Fourth, to expand related convergence markets, a variety of activities were initiated. This included not only the activities of the convergence alliances, but the outcomes of the activities were also publicized to develop further technological and organizational collaborations. Exhibitions, seminars, forums, conferences, and associated presentations were produced for the spread of the convergence alliance, and positive feedback included new membership and increased market performance. Additionally, some convergence alliances are providing web-based services for promoting their activities and the diffusion of their performance. 


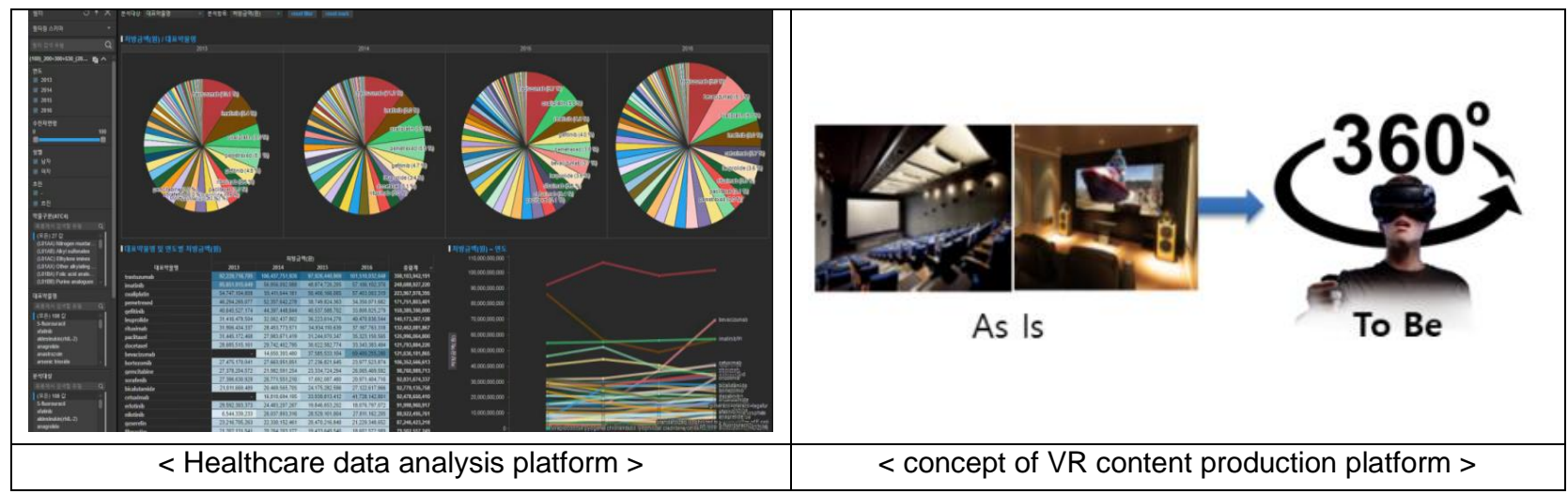

Figure 1. Examples of business model created by convergence alliance

In addition to these four types of outcome, in association with government policy and strategy, policy studies on industry infrastructure and promotion were undertaken, and education programs for training convergence experts were implemented. These activities had an incentive role for firms and organizations to participate in the convergence alliance, and currently, more than 550 participants in 17 convergence alliances are working together. The major activities of convergence alliances are summarized in Table 2. While the purpose of organizing each convergence alliance is almost identical in promoting collaboration, the sector, primary activities, and focuses are distinctive.

In addition to the four types of outcome aforementioned, policy studies such as industry infrastructure and promotion in association with government policy and strategy were made, and education programs for training convergence experts were operated. Such various activities played a role as incentives for firms and organizations to participate in convergence alliance. Currently more than 550 participants in 17 convergence alliances are working together. Major activities of convergence alliances were summarized in Table 2. While the purpose of organizing each convergence alliance is almost identical in promoting collaboration, sector, primary activities and focuses are distinctive each other.

\section{Examples of existing collaboration platforms}

The Open Handset Alliance (OHA) is a representative example of a collaboration platform. Led by Google, 34 firms including device manufacturers, application developers, telecoms, and semiconductor manufacturers founded the OHA in
November 2007, and it has subsequently included over eighty members. They collaborated to develop Android, a mobile operating system based on Linux. Since its establishment, Android has become the de facto standard mobile operating system, and its market share exceeds that of Apple's iOS, which once dominated the mobile operating system market [11].

The Industrial Internet Consortium (IIC) is another representative example. Over 160 firms including GE, IBM, and Intel were the founding members whose main objective in 2014 was to develop and commercialize the industrial Internet including the Internet of Things (IoT). Their aim was for IoT and Big Data-based industrial Internet development to be adopted in energy, healthcare, smart cities, transportation, and manufacturing. Rather than setting industry standards, the IIC was formed to promote technology development and multinational commercialization. While the IIC demonstrates similar processes to the Industrie 4.0 consortium in Germany, it leads the industrial Internet by pursuing rapid commercialization.

The GIGA IoT alliance founded in August 2015 is a good example of a collaboration platform in Korea. Led by one of the largest telecommunication companies, it consists of four hundred domestic and international firms, developing, verifying, and commercializing IoT-based business models. Ultimately, it is attempting to lead in the global IoT market and build domestic IoT ecosystem infrastructure. Specifically, as a central role, the leader of the GIGA IoT alliance is investing directly into new business models and preemptively adopting them in its business field. Several examples of domestic and international collaboration platforms are summarized in Table 3.

Reviewing the existing collaboration platforms, two distinct characteristics emerged. First, specific interests 
Table 2. Major activities of convergence alliances

\begin{tabular}{|c|c|c|c|c|c|}
\hline Sector & $\begin{array}{c}\text { Business } \\
\text { model }\end{array}$ & Deregulation & $\begin{array}{c}\text { Technology } \\
\text { R\&D }\end{array}$ & Outcome spread & Etc. \\
\hline Automotive & 0 & & 0 & o (web-service) & $\mathrm{o}(\mathrm{HR})$ \\
\hline New material & & & 0 & 0 & \\
\hline Biotechnology & 0 & & 0 & 0 & \\
\hline New energy & 0 & 0 & & 0 & \\
\hline Energy saving system (ESS) & 0 & 0 & & 0 & o (policy) \\
\hline Hydrogen & & & 0 & o (web-service) & o (policy) \\
\hline Consumer goods & & & 0 & 0 & \\
\hline Zero energy building (ZEB) & 0 & & 0 & 0 & \\
\hline Electric vehicle and secondary battery & & & & 0 & \\
\hline Robot & & 0 & 0 & & \\
\hline Distribution & & & 0 & 0 & o (policy) \\
\hline Electronic components & 0 & & 0 & & o (policy) \\
\hline Augmented/Virtual reality & 0 & & 0 & 0 & o (policy) \\
\hline IoT appliance and smart home & 0 & & & & $\mathrm{o}(\mathrm{HR})$ \\
\hline Medical device & & & 0 & 0 & o (standard) \\
\hline Aviation & & & 0 & & \\
\hline Nanotechnology & & & 0 & 0 & o (policy) \\
\hline
\end{tabular}

or common objectives were the key reasons for establishing the collaboration platform. That is, the development of specific technology and infrastructure for market expansion was the common objective of the members. Technology adoption in the marketplace was promoted as a de facto standard, and thus it was the main driver for members to participate in the collaboration platform.

Second, one particular firm took the initiative and established interfirm collaboration. In pursuing the aforementioned common objective, these firms had the strongest incentive for the achievement of collaboration. This again demonstrates the importance of preemption in the new market. For example, Google with the core technology of Android, initiated, organized, and operated OHA. At the time, Google already had a dominant position as an Internet search engine, and it hoped to leverage its competence in the mobile industry [12]. Critically, this enabled Google to lead in the mobile network and smartphone era. In the case of IIC, GE also demonstrated a stronger leadership role than other members of the collaboration platform. GE's transition from manufacturer to ICTbased system integration service provider, and thus the industrial Internet, was a critical tool for GE [13].

\section{The characteristics of convergence alliances}


Table 3. Examples of collaboration platform

\begin{tabular}{|c|c|c|c|}
\hline Name & Members & Main objective & Establishment \\
\hline Open Handset Alliance & $\begin{array}{c}84 \text { members such as Google, } \\
\text { Samsung electronics, } \\
\text { Qualcomm, and Intel }\end{array}$ & $\begin{array}{c}\text { Diffusion of Android, Linux based } \\
\text { mobile operating system }\end{array}$ & 2007 \\
\hline GENIVI Alliance & $\begin{array}{c}140 \text { members such as BMW, } \\
\text { Hyundai motors, Bosch, and } \\
\text { Fujitsu }\end{array}$ & $\begin{array}{l}\text { Development of infotainment and } \\
\text { connectivity system in an open } \\
\text { platform based car }\end{array}$ & 2009 \\
\hline HySUT & $\begin{array}{l}35 \text { members such as Honda, } \\
\text { Toyota, and JX energy }\end{array}$ & $\begin{array}{c}\text { Building hydrogen supplying } \\
\text { infrastructure, set of international } \\
\text { standard }\end{array}$ & 2009 \\
\hline $\begin{array}{l}\text { Allseen Alliance (Merged } \\
\text { by Open Connectivity } \\
\text { Foundation in 2016) }\end{array}$ & $\begin{array}{c}80 \text { members such as } \\
\text { Qualcomm, LG, MS, and } \\
\text { Canon }\end{array}$ & $\begin{array}{l}\text { Development of open software for } \\
\text { interoperable device and service } \\
\text { (AllJoyn) }\end{array}$ & 2013 \\
\hline H2USA & $\begin{array}{c}47 \text { members such as Benz, } \\
\text { Hyundai motors, and GM }\end{array}$ & $\begin{array}{l}\text { Establishment of hydrogen station } \\
\text { infrastructure }\end{array}$ & 2013 \\
\hline $\begin{array}{l}\text { Industrial Internet } \\
\text { Consortium }\end{array}$ & $\begin{array}{c}160 \text { members such as GE, } \\
\text { AT\&T, Cisco, and IBM }\end{array}$ & $\begin{array}{l}\text { Development and diffusion of } \\
\text { industrial Internet technology }\end{array}$ & 2014 \\
\hline Open Automotive Alliance & $\begin{array}{c}70 \text { members such as Google, } \\
\text { Hyundai motors, Audi, and } \\
\text { NVidia }\end{array}$ & Promotion of automobile Android & 2014 \\
\hline Alliance for Open Media & $\begin{array}{c}24 \text { members such as Google, } \\
\text { Netflix, Cisco, and Amazon }\end{array}$ & $\begin{array}{l}\text { Technology development of open } \\
\text { source video codec }\end{array}$ & 2015 \\
\hline GIGA loT Alliance & $\begin{array}{l}100 \text { members such as } \\
\text { Samsung electronics, SKT, LG, } \\
\text { NTT docomo }\end{array}$ & $\begin{array}{l}\text { Development of loT business } \\
\text { model, empirical test, and } \\
\text { commercialization }\end{array}$ & 2015 \\
\hline $\begin{array}{l}\text { Industrial Value Chain } \\
\text { Initiative }\end{array}$ & $\begin{array}{c}220 \text { members such as } \\
\text { Mitsubishi, Siemens, Sony, and } \\
\text { Softbank }\end{array}$ & $\begin{array}{c}\text { Standard-setting for inter-factory } \\
\text { connectivity and security } \\
\text { technology }\end{array}$ & 2015 \\
\hline
\end{tabular}

Compared to international collaboration platforms, convergence alliances in Korea have unusual characteristics. First, convergence alliances were initially organized around the big picture of a new industry and later set common objectives through consistent discussions among their members. Generally, collaboration platforms have specific objectives such as the development and commercialization of technology or products for financial success. On the contrary, the objective of a convergence alliance is set by practical operating groups, and thus, it can organize branches and working groups, systematically addressing feasibility and effective performance for their members. Representatively, the convergence alliance in the robotics industry did not initially set a specific goal. After a comprehensive discussion by its alliance members, it decided to focus on a specific purpose robot and set related objectives. A researcher in a public organization said,

"We consistently reviewed several types of robot, even before launching the convergence alliance. Rehabilitation robots were selected as the most urgent field for commercialization. Most of the activities of the convergence alliance will be in the rehabilitation robot field for the next few months."

After completing activities based on rehabilitation robots, a collaboration robot was selected as the next topic for the robotics industry convergence alliance. Comprehensively considering the economic context and social environment, specific objectives can be set and rolled out promptly. 
Second, the outcome of a convergence alliance is not subject to joint R\&D. Most collaboration platforms driven by corporate organizations conduct joint $R \& D$ and enter the new market with the result of this joint R\&D. However, convergence alliances can address a variety of objectives such as creative convergence business models, exhibitions, and conferences with outcomes, market expansion activities, and suggestions for deregulation. For example, a convergence alliance in the energy sector only emphasized market diffusion, institutional reform, and infrastructure construction. A senior manager in a public organization said,

"In terms of $\mathrm{R} \& \mathrm{D}$ and technology, private firms are already launching high-quality products. A convergence alliance, thus, does not need to deal with this technology area. Rather, product diffusion and business model developments will be more valuable to its members."

These new types of collaboration platform can be characterized by focusing on the institutional reform and market diffusion that are difficult for single organizational units to carry out.

Third, convergence alliances in Korea include various innovation actors such as financial organizations, research institutes, and government agencies. However, it is clear that the formation of convergence alliances is initiated by private corporate entities. This is different from other existing collaboration platforms, which were mainly driven by the Korean government. Only when there is a lack of the required capacity and competency for the convergence alliance, it is necessary to include the participation of other innovation actors after the establishment of a convergence alliance. By involving innovation actors in convergence alliances, it is possible to have productive discussions, create new business models, set technology standards, and amend existing regulations. In the case of hydrogen convergence alliance's deregulation activities, for example, this was achieved through the hard work of many stakeholders to remove negative cognition. Thus, the members of the convergence alliance for hydrogen attempted to solve a difficult problem. The secretary general of a publicly and privately funded organization said,

"It is still insufficient in terms of organization. Even though there is support from ministries and agencies, deregulation is still very difficult and limited. We believe that we are able to solve these problems with the various alliance activities for reforming the regulatory framework and by building a hydrogen infrastructure."
In practice, the hydrogen convergence alliance supports legislation and holds conferences and forums in Congress for the establishment of hydrogensupporting laws. In terms of spread, it successfully attracts both political and market-based attention.

\section{Discussion and implications}

The literature on technology innovation and management mainly focuses on the factors that influence the success of alliances such as their absorptive capacity [4], appropriability [5], SMEs [6], and external resources [14]. In addition to these current concepts, convergence alliances include the context of heterogeneous knowledge. This can eventually explain every collaboration activity in terms of technology, product, service, and organization.

According to the characteristics of convergence alliances, some significant points can be made. First, during the process of seeking their common objectives, participants of each convergence alliance can maintain and focus their competence along with their absorptive capacity and appropriability. Second, a variety of objectives can lead participants to reduce the risk of innovative activities, which are only possible with heterogeneous knowledge. Third, the participation of various actors, especially, SMEs can expand the openness of collaboration platforms in order to access external resources. These influencing factors of convergence alliances can, therefore, determine how the country can utilize new tools and develop new pathways for further economic growth.

Several further implications can also be derived. First, from an economic growth viewpoint, convergence alliances should be organized toward a combination of manufacturing and service industries so that Korea can increase the core competency of the manufacturing industry. Since the 2008 financial crisis, an emphasis on value-added manufacturing, including advanced manufacturing plans and reshoring support, has been a mainstream of economic policy worldwide. While a formation with only specific industries is not intended, convergence alliances should be organized by coupling manufacturing and service industries in order to enhance the comparative advantage of Korea's manufacturing industry. For example, the structure and objectives of automobile convergence alliance and electronic component convergence alliance demonstrate the direction to the value-added manufacturing industry with service.

Second, more opportunities for SMEs to participate in the convergence alliance should be made available. SMEs are primary sources for new ideas and external knowledge [15]. According to the Ministry of Trade, 
Industry and Energy, the participation share of SMEs in convergence alliances as of October 2017 was quite high, accounting for 68.1 percent, and this is not evident in any other collaboration platform. Thus, the convergence alliance can be a platform for realizing the creative ideas of SMEs.

Third, although most collaboration platforms set R\&D activities as their priority, the opportunistic behavior of each member frequently appears at a critical moment. Corporations are strategically driven by their own interests such as their technological appropriability and their share of intellectual property rights. For example, although most members of the OHA collaborated to diffuse the use of Android, their support to improve the technology was exclusive and restricted [16]. Therefore, their attitude should be inclined to collaborate in terms of organizational context, human resource, and cultural context, without considering any opportunistic behaviors.

Fourth, new objectives such as standards development and demonstration projects should be set. Existing standards, certificates, and institutions are not appropriate to new convergence products and services and result in market entry failure. Therefore, setting new standards and certification levels and approving de jure standards can be a new objective of convergence alliances. Another example is that convergence alliances could be used as a test pilot organization in the commercialization process after developing business models. Convergence alliances could also verify new bills and amended rules to reform regulations for new industry and convergence product/service commercialization.

Finally, relevant policy action and governmentdriven support are necessary for the efficient implementation of convergence alliances and the delivery of practical outcomes. Collaboration is an appropriate tool for attempting risky but challengeable R\&D, which cannot be conducted by a single organization. For promoting joint $R \& D$, government support is a strong incentive for firms and other innovation actors. Even with incentives for convergence alliances, however, the autonomous operation of organizations should be guaranteed, and government intervention should be avoided, in order to enable successful performance. Only institutional organizations are necessary for supporting and organizing convergence alliances.

\section{Conclusion and limitations}

In order to develop a new industrial growth engine, Korea has attempted to introduce various policies. Among those, a new type of collaboration platform, convergence alliances, are emerging as a new instrument. Therefore, this research explored convergence alliances and their characteristics using a case study analysis based on in-depth interviews. Although the scope and focus of convergence alliance activities are different for each group, the authors confirmed that they share the common goal of developing a new growth engine and thus they promote similar activities for each industry.

As a practical contribution, this study provides evidence for countries that are seeking a new growth engine. Furthermore, this study contributes to technology innovation and management research; convergence alliances can open a new window of opportunity as a new type of collaboration platform research.

This study was based on the qualitative analysis of in-depth interviews and extant publications. Although external researchers validated the collected data, interviewees were the core actors of each convergence alliance. This can weaken the objective perspective and could become a limitation. For further research, quantitative analysis could enhance the objectives and explore the structural evolution of convergence alliances, for example, by using network analysis to examine collaboration, centrality, and closeness.

\section{Acknowledgement}

This work was supported by "Industrial convergence new product suitability-certification support," "Industry-convergence alliance support project," and "A program on building industrial convergence culture furtherance and operating industrial convergence acceleration ombudsman" granted from Ministry of Trade, Industry and Energy, Republic of Korea.

\section{References}

[1] L. E. Westphal, "Industrial Policy in an Export-Propelled Economy: Lessons from South Korea's Experience," Journal of Economic Perspectives, Vol. 4, No. 3, pp. 41-59, 1990.

[2] K. Schwab, "The fourth industrial revolution." In: World Economic Forum, pp. 51-59, 2016.

[3] Ministry of Trade, Industry and Energy, "Industrial Policy of New Administration.”, 2017.

[4] C. Lin, Y. -J. Wu, C. Chang, W. Wang, \& C. -Y. Lee, "The alliance innovation performance of R\&D alliances - the absorptive capacity perspective," Technovation, Vol. 32, No. 5, pp. 282-292, 2012. 
[5] A. Capaldo \& A. M. Petruzzelli, "In search of alliancelevel relational capabilities: Balancing innovation value creation and appropriability in R\&D alliances," Scandinavian Journal of Management, Vol. 27, No. 3, pp. 273-286, 2011.

[6] F. -J. Lin, S. -H. Wu, M. -S. Hsu, \& C. Perng, "The determinants of government-sponsored R\&D alliances," Journal of Business Research, Vol. 69, No. 11, pp. 51925195,2016

[7] B. Diirr \& C. Cappelli, "A systematic literature review to understand cross-organizational relationship management and collaboration." In: 51st Hawaii International Conference on System Sciences, 2018.

[8] R. K. Yin, Case Study Research: Design and Methods (3rd ed.). Sage Publications. 2003.

[9] T. Papaioannou, D. Wield, \& J. Chataway, "Knowledge ecologies and ecosystems? An empirically grounded reflection on recent developments in innovation systems theory," Environment and Planning C: Government and Policy, Vol. 27, No. 2, pp. 319-339, 2009.

[10] J. W. Creswell \& D. L. Miller, "Determining validity in qualitative inquiry." Theory into Practice, Vol. 39, No. 3, pp. 124-130, 2000
[11] H. Kim, D. Lee, \& J. Hwang, "Measuring the efficiency of standardisation policy using meta-frontier analysis: A case of mobile platform standardization." International Journal of Mobile Communications, Vol. 14, No. 1, pp. 79-98, 2016.

[12] P. E. Ramirez-Correa, F. J. Rondan-Cataluña, \& J. Arenas-Gaitán, "Predicting behavioral intention of mobile Internet usage." Telematics and Informatics, Vol. 32, No. 4, pp. 834-841, 2015.

[13] D. Merfeld, "GE is in a startup state of mind." ResearchTechnology Management, Vol. 57, No. 6, pp. 26-32, 2014.

[14] H. W. Chesbrough, Open Innovation: The New Imperative for Creating and Profiting from Technology. Harvard Business Press. 2003.

[15] J. Shumpeter, Capitalism, Socialism and Democracy. Harper Collins. 1950.

[16] S. Koch \& M. Kerschbaum, "Joining a smartphone ecosystem: Application developers' motivations and decision criteria." Information and Software Technology, Vol. 56, No. 11, pp. 1423-1435, 2014. 